\title{
REPLENISHMENT LOT SIZE AND NUMBER OF SHIPMENTS FOR EPQ MODEL DERIVED WITHOUT DERIVATIVES
}

\author{
Kuang-Ku Chen ${ }^{1}$, Singa Wang Chiu ${ }^{2, *}$ \\ ${ }^{1}$ Department of Accounting, College of Management, \\ National Changhua University of Education, Changhua 500, Taiwan \\ ${ }^{2}$ Department of Business Administration, Chaoyang University of Technology, \\ Taichung 413, Taiwan \\ swang@cyut.edu.tw
}

\begin{abstract}
This paper investigates optimal replenishment lot size and optimal number of shipments for economic production quantity (EPQ) model with rework process using an algebraic approach. The classic EPQ model assumes a perfect quality production for all items produced and a continuous issuing policy for satisfying customer's demand. However, in a real life vendor-buyer integrated-production-inventory system, a multidelivery policy is commonly used in lieu of a continuous issuing policy and generation of defective items during a production run seems to be inevitable. A recent published work examined such an identical problem using mathematical modeling and differential calculus to derive the optimal replenishment lot size and optimal number of deliveries that minimizes overall production-inventory-shipment costs. This paper proposes a straightforward algebraic approach to replace the use of calculus on the cost function for determining optimal production-shipment policies. It also presents a simpler form for calculating the long-run average cost for such an imperfect EPQ problem.
\end{abstract}

Keywords-Replenishment lot size; Multiple shipments; Algebraic approach; Random defective rate; EPQ model; Rework

\section{INTRODUCTION}

Two fundamental questions that need to be answered by inventory controllers for items they routinely replenish are "when should a replenishment lot be initiated?" and "how many to be refilled in a lot?" in order to minimize the long-run average cost [1]. The economic production quantity (EPQ) model is often used by production and inventory managers to assist them in addressing the aforementioned issues [2]. The classic EPQ model assumes a continuous inventory issuing policy for satisfying product demand. However, in a real life vendor-buyer integrated production-inventory system, multiple or periodic deliveries of finished products are commonly adopted. As a result, another issue to be addressed is "how many shipments should a replenishment lot be broken down to?" so that the overall costs can be minimized.

Goyal [3] first considered an integrated inventory model for a single supplier-single customer problem. He proposed a method that is typically applicable to those inventory problems where a product is procured by a single customer from a single supplier. Example was given to illustrate the method proposed. Studies have since been carried out to address various aspects of supply chain optimization [4-8]. Banerjee [4] studied an integrated economic lot-size model for the purchaser and vendor. Sarker and Khan [6] 
examined a manufacturing system that procures raw materials from suppliers in a lot and processes them into finished products which are then delivered to outside buyers at fixed points in time. A general cost model was formulated considering both raw materials and finished products. Using this model, a simple procedure was developed to determine the optimal ordering policy for raw materials as well as the manufacturing batch size, so that the overall costs for such a supply chain system can be minimized. Siajadi et al. [8] presented a methodology to obtain the joint economic lot size in the case where multiple buyers are demanding one type of item from a single vendor. They proposed a model to minimize the joint total relevant cost (JTRC) for both vendor and buyer(s). They also considered the two-buyer and more than two-buyer cases, and obtained the exact and approximate optimum solutions, respectively.

The classic EPQ model also assumes that all items produced are of perfect quality. It is unrealistic, because in real-life production system, due to process deterioration and other various factors, generation of defective items is inevitable. Studies have been carried out to enhance the classic EPQ model by addressing the issue of defective items produced [9-13]. The nonconforming items sometimes can be reworked and repaired hence the overall production costs can be significantly reduced [14-22]. Jamal et al. [16] studied the optimal manufacturing batch size with rework process at a single-stage production system. Cases of rework being completed within the same production cycle, and rework being done after $\mathrm{N}$ cycles are examined. They developed mathematical models for each case and derived total system costs and optimal batch sizes accordingly. Chiu et al. [22] investigated the optimal replenishment lot size and optimal number of shipments for economic production quantity (EPQ) model with rework. They used the mathematical modeling together with the conventional derivatives on the cost function of the proposed system, to prove its optimality and derived the optimal replenishment production-shipments decisions respectively.

A few recent papers [23-25] for instance, Grubbström and Erdem [23] and Cárdenas- Barrón [24], they proposed algebraic approaches for solving economic order quantity (EOQ) model with backlogging and EPQ model with shortages respectively, without reference to the use of derivatives, neither applying the first-order nor the second-order differentiations. This paper re-examines the EPQ model (considered by Chiu et al. [22]) with rework and multi-delivery policy using algebraic approach, to demonstrate that the optimal replenishment production-shipments policies as well as the long-run average system costs can all be derived without derivatives.

\section{PROBLEM STATEMENT AND MATHEMATICAL MODELLING}

Reexamine the EPQ model with multi-delivery policy and reworking of random defective items produced, solving by the use of conventional approach [22]. It assumes that during regular production time, there is an $x$ portion of defective items produced randomly at a production rate $d$. All defective items are assumed to be repairable and are reworked at a rate $P_{1}$ after the end of a production run, in each cycle. The constant production rate $P$ is assumed to be larger than the sum of demand rate $\lambda$ and production rate of defective items $d$. That is $(P-d-\lambda)>0$, where $d=P x$.

A multi-delivery policy is considered in this study and it is also assumed that the finished items can only be delivered to customers if the whole lot is quality assured at 
the end of rework. The fixed-quantity $n$ installments of finished batch are delivered to customers, at a fixed interval of time during the production downtime $t_{3}$ (see Figure 1).

For the purpose of easing readability, the notation used in this paper is identical to that of Chiu et al [22], refer to Nomenclature listed below.

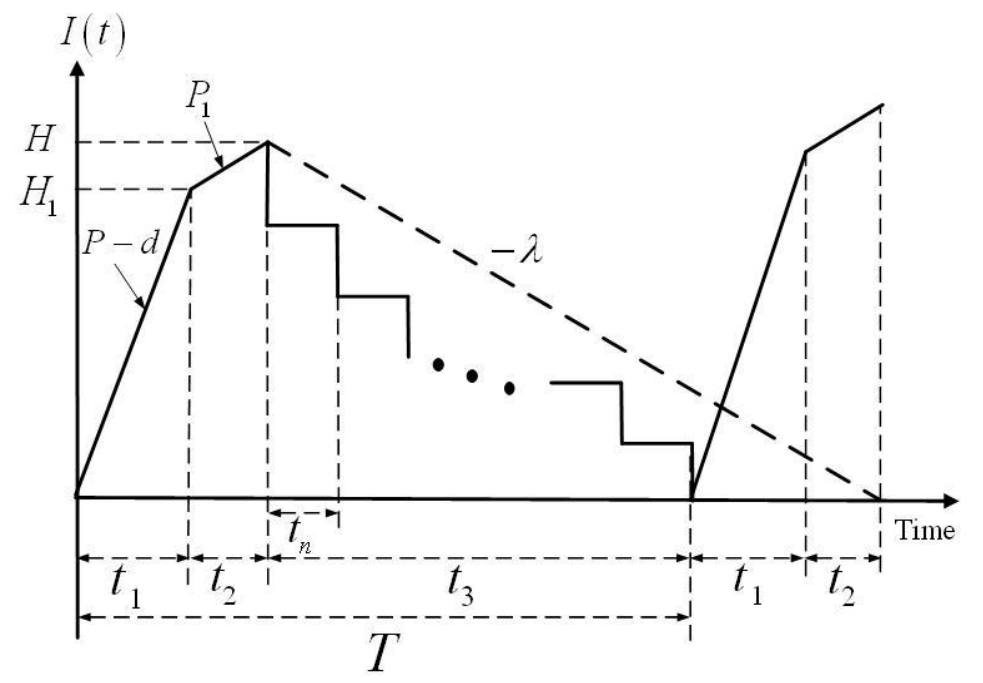

Figure 1: On-hand inventory of perfect quality items in an EPQ model with a multi-shipment policy and rework [22]

\section{NOMENCLATURE:}

$K=$ setup cost per production run,

$C=$ unit manufacturing cost,

$C_{\mathrm{R}}=$ unit rework cost,

$P_{1}=$ rate of rework,

$d=$ production rate of defective items,

$Q=$ a decision variable - production lot size to be determined for each cycle,

$h$ = unit holding cost,

$h_{1}=$ holding cost for each reworked item,

$n$ =decision variable, denotes the number of fixed-quantity installments of the finished batch to be delivered to the customers,

$K_{1}=$ fixed delivery cost per shipment,

$C_{\mathrm{T}}=$ unit delivery $\cos t C_{\mathrm{T}}$,

$t_{1}=$ the production uptime for the proposed EPQ model,

$t_{2}=$ time required for reworking of defective items,

$t_{3}=$ time required for delivering all quality assured finished products,

$H_{1}=$ maximum level of on-hand inventory in units when regular production process ends,

$H=$ the maximum level of on-hand inventory in units when rework process finishes,

$t_{\mathrm{n}}=\mathrm{a}$ fixed interval of time between each installment of finished products delivered during production downtime $t_{3}$, 
$T$ = cycle length,

$I(t)=$ on-hand inventory of perfect quality items at time $t$,

$T C(Q, n)=$ total production-inventory-delivery costs per cycle for the proposed model,

$\mathrm{E}[T C U(Q, n)]=$ the long-run average costs per unit time for the proposed model.

The total production-inventory-delivery costs per cycle $T C(Q, n)$ consists of variable production cost, setup cost, variable rework cost, variable delivery cost, fixed delivery cost, variable holding cost for items reworked, holding costs during periods $t_{1}$ and $t_{2}$, and holding cost for finished goods during delivery time $t_{3}$ where $\mathrm{n}$ fixed-quantity installments of finished batch are delivered by request to customers at a fixed interval of time. Therefore, $T C(Q, n)$ is

$$
\begin{aligned}
T C(Q, n) & =C Q+K+C_{R}[x Q]+C_{T}[Q]+n K_{1}+h_{1} \cdot \frac{P_{1} \cdot t_{2}}{2} \cdot\left(t_{2}\right) \\
& +h\left[\frac{H_{1}+d t_{1}}{2}\left(t_{1}\right)+\frac{H_{1}+H}{2}\left(t_{2}\right)+\left(\frac{n-1}{2 n}\right) H t_{3}\right]+\frac{h_{2}}{2}\left[\frac{H}{n} t_{3}+T\left(H-\lambda t_{3}\right)\right]
\end{aligned}
$$

Using mathematical modeling and analysis, the long-run average costs per unit time for the proposed model, $\mathrm{E}[T C U(Q, n)]$ can be derived as follows [22]:

$$
\begin{aligned}
E[T C U(Q, n)]= & \frac{E[T C(Q, n)]}{E[T]}=C \lambda+\frac{\left(K+n K_{1}\right) \lambda}{Q}+C_{R} E[x] \lambda+C_{T} \lambda+\frac{h Q \lambda}{2 P} \\
& +\frac{h Q \lambda}{2 P_{1}}\left[2 E[x]-(E[x])^{2}\right]+\left(\frac{n-1}{n}\right)\left[\frac{h Q}{2}-\frac{h Q \lambda}{2 P}-\frac{h Q E[x] \lambda}{2 P_{1}}\right] \\
& +\frac{h_{1}(E[x])^{2} Q \lambda}{2 P_{1}}+\left(\frac{1}{n}\right) \frac{h_{2} Q}{2}+\left(1-\frac{1}{n}\right) \frac{h_{2} Q \lambda}{2 P}+\frac{h_{2} Q}{2}\left[\left(1-\frac{1}{n}\right) \frac{E[x] \lambda}{P_{1}}\right]
\end{aligned}
$$

\section{OPTIMAL SOLUTIONS DERIVED WITHOUT DERIVATIVES}

This paper employs algebraic approach instead of using the conventional differential calculus on the long-run average cost function $\mathrm{E}[T C U(Q, n)]$ for proof of its optimality as well as obtaining the optimal production-shipment policies.

Because the decision variables are $Q$ and $n$, we identify that Equation (2) has terms for the constants, $Q, Q^{-1}, n Q^{-1}$, and $Q n^{-1}$ as follows.

$$
E[T C U(Q, n)]=Z_{0}+Z_{1}(Q)+Z_{2}\left(Q^{-1}\right)+Z_{3}\left(n Q^{-1}\right)+Z_{4}\left(Q n^{-1}\right)
$$

Where $Z_{0}, Z_{1}, Z_{2}, Z_{3}$, and $Z_{4}$ denote the following:

$$
\begin{aligned}
& Z_{0}=C \lambda+C_{R} E[x] \lambda+C_{T} \lambda \\
& Z_{1}=+\left(\frac{h}{2}\right)\left[1+\frac{\lambda E[x]}{P_{1}}[1-E[x]]+\left(\frac{h_{2}}{2}\right)\left[\frac{\lambda}{P}+\frac{\lambda E[x]}{P_{1}}\right]+\left(\frac{h_{1}}{2}\right) \frac{\lambda(E[x])^{2}}{P_{1}}\right. \\
& Z_{2}=K \lambda
\end{aligned}
$$




$$
\begin{aligned}
& Z_{3}=K_{1} \lambda \\
& Z_{4}=\left[1-\frac{\lambda}{P}-\frac{E[x] \lambda]}{P_{1}}\right]\left(\frac{h_{2}}{2}-\frac{h}{2}\right)
\end{aligned}
$$

With further rearrangements, Equation (3) becomes

$$
\begin{aligned}
E[T C U(Q, n)] & =Z_{0}+Q^{-1}\left[Z_{1} \cdot Q^{2}+Z_{2}\right]+Q \cdot\left(n^{-1}\right)\left[Z_{3}\left(n Q^{-1}\right)^{2}+Z_{4}\right] \\
E[T C U(Q, n)] & =Z_{0}+Q^{-1}\left[\left(\sqrt{Z_{1}} \cdot Q\right)^{2}+\left(\sqrt{Z_{2}}\right)^{2}-2\left(\sqrt{Z_{1}} \cdot Q\right)\left(\sqrt{Z_{2}}\right)\right] \\
& +Q \cdot\left(n^{-1}\right)\left[\left(\sqrt{Z_{3}}\left(n Q^{-1}\right)\right)^{2}+\left(\sqrt{Z_{4}}\right)^{2}-2 \sqrt{Z_{3}} \sqrt{Z_{4}}\left(n Q^{-1}\right)\right] \\
& +Q^{-1}\left[2\left(\sqrt{Z_{1}} \cdot Q\right)\left(\sqrt{Z_{2}}\right)\right]+Q \cdot\left(n^{-1}\right)\left[2 \sqrt{Z_{3}} \sqrt{Z_{4}}\left(n Q^{-1}\right)\right] \\
E[T C U(Q, n)] & =Z_{0}+Q^{-1}\left[\sqrt{Z_{1}} \cdot Q-\sqrt{Z_{2}}\right]^{2}+Q\left(n^{-1}\right)\left[\sqrt{Z_{3}}\left(n Q^{-1}\right)-\sqrt{Z_{4}}\right]^{2} \\
& +2 \sqrt{Z_{1} \cdot Z_{2}}+2 \sqrt{Z_{3} \cdot Z_{4}}
\end{aligned}
$$

From Equation (11), it is noted that if the following square terms equal zero, then $\mathrm{E}[\operatorname{TCU}(Q, n)]$ is minimized

$$
\begin{aligned}
& Q^{-1}\left[\sqrt{Z_{1}} \cdot Q-\sqrt{Z_{2}}\right]^{2}=0 \\
& Q\left(n^{-1}\right)\left[\sqrt{Z_{3}}\left(n Q^{-1}\right)-\sqrt{Z_{4}}\right]^{2}=0
\end{aligned}
$$

or

$$
Q^{*}=\sqrt{\frac{Z_{2}}{Z_{1}}}
$$

and

$$
n^{*}=\sqrt{\frac{Z_{4}}{Z_{3}}} \cdot Q^{*}
$$

Substituting Equations (5) and (6) in Equation (14), the optimal replenishment lot size $Q^{*}$ can be obtains:

$$
Q^{*}=\sqrt{\frac{2 K \lambda}{h\left[1+\frac{\lambda E[x]}{P_{1}}[1-E[x]]\right]+h_{2}\left[\frac{\lambda}{P}+\frac{\lambda E[x]}{P_{1}}\right]+h_{1} \cdot \frac{\lambda(E[x])^{2}}{P_{1}}}}
$$

Substituting Equation (16) in Equation (15), the optimal number of shipments is 


$$
n^{*}=\sqrt{\frac{K\left[1-\frac{\lambda}{P}-\frac{E[x] \lambda}{P_{1}}\right]\left(h_{2}-h\right)}{K_{1} \cdot\left\{h\left[1+\frac{\lambda E[x]}{P_{1}}[1-E[x]]+h_{2}\left[\frac{\lambda}{P}+\frac{\lambda E[x]}{P_{1}}\right]+h_{1} \cdot \frac{\lambda(E[x])^{2}}{P_{1}}\right\}\right.}}
$$

It is noted that Equation (17) is identical to Equation (21) as was given in Chiu et al [22]. From Equation (7) it follows that the optimal cost function $E\left[T C U\left(Q^{*}, n^{*}\right)\right]$ is

$$
E\left[\operatorname{TCU}\left(Q^{*}, n^{*}\right)\right]=Z_{0}+2 \sqrt{Z_{1} \cdot Z_{2}}+2 \sqrt{Z_{3} \cdot Z_{4}}
$$

\section{NUMERICAL EXAMPLE}

The aforementioned results derived by algebraic approach, especially Equations (16) to (18) are verified in this section using the same numerical example [22]. Reconsider that customer demand of a product is 3,400 units per year and it can be produced at an annual rate of 60,000 units. During the production, there is a random defective rate $x$ which follows a uniform distribution over an interval [0, 0.3]. All defective items produced are considered to be repairable and a rate of rework $P_{1}=2,200$ units per year. Additional parameters used here include:

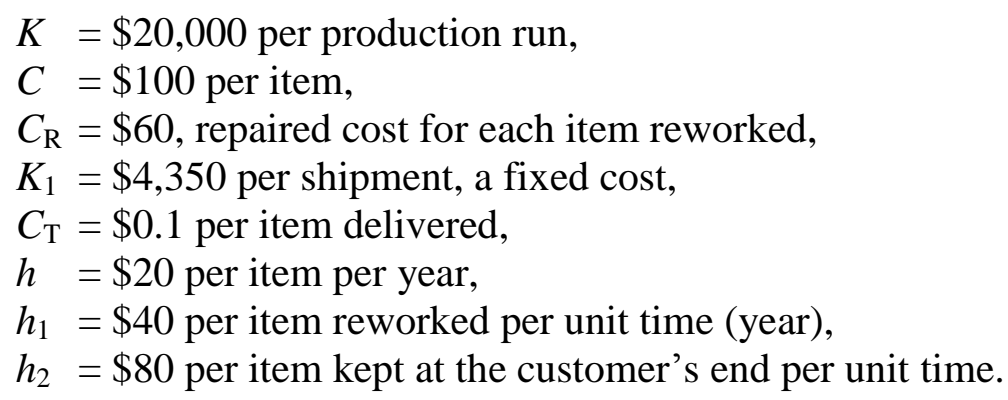

By using Equations (17), (16), and (18), the optimal number of shipments $n^{*}=2$, the optimal replenishment production lot size $Q^{*}=1,673$, and the optimal long-run average cost $\mathrm{E}\left[T C U\left(Q^{*}, n^{*}\right)\right]=\$ 487,617$ can all be obtained. These results are verified and they are identical to that were given by Chiu et al [22].

Because the number of shipments $n^{*}$ only takes on integer value, one should use Equation (2) to determine the optimal integer value of $n^{*}$ first, then plug it into Equation (3) to form a new set of formulas (i.e. Eqs. (4) to (12)) with single variable Q, and determine (using Eq. (14)) the optimal Q* accordingly.

\section{CONCLUSION}

This paper determines the optimal replenishment lot size and the optimal number of shipments for EPQ model with rework process using an algebraic approach. It shows that economic lot size $Q^{*}$, optimal number of delivery $n^{*}$ and the long-run average production-inventory-delivery costs $\mathrm{E}\left[T C U\left(Q^{*}, n^{*}\right)\right]$ for the proposed EPQ model can all be derived without derivatives. 
This paper also reveals a simpler form (i.e. Equation (18) for calculating the optimal cost function $\mathrm{E}\left[T C U\left(Q^{*}, n^{*}\right)\right]$. The algebraic approach demonstrated in this paper, may enable practitioners or students who with little or no knowledge of calculus to learn or handle with ease the real-life EPQ model.

\section{ACKNOWLEDGEMENTS}

The authors greatly appreciate the National Science Council of Taiwan for supporting this research under grant number: NSC 99-2410-H-324-007-MY3.

\section{REFERENCES}

1. R. J. Tersine, Principles of Inventory and Materials Management. PTR Prentice- Hall, New Jersey, 121-129, 1994.

2. E. A. Silver, D. F. Pyke, and R. Peterson, Inventory Management and Production Planning and Scheduling, John Wiley \& Sons, Inc., New York, 151-172, 1998.

3. S. K. Goyal, Integrated Inventory Model for a Single Supplier - Single Customer Problem, International Journal of Production Research 15, 107-111, 1977.

4. A. Banerjee, A joint economic-lot-size model for purchaser and vendor, Decision Sciences 17, 3, 292-311, 1986.

5. L. Lu, A one-vendor multi-buyer integrated inventory model, European Journal of Operational Research 81, 312-323, 1995.

6. R. A. Sarker and L. R. Khan, Optimal batch size for a production system operating under periodic delivery policy, Computers and Industrial Engineering 37, 711-730, 1999.

7. P. C. Yang and H. M. Wee, A single-vendor and multiple-buyers productioninventory policy for a deteriorating item, European Journal of Operational Research 143, 3, 570-581, 2002.

8. H. Siajadi, R. N. Ibrahim, and P. B. Lochert, Joint economic lot size in distribution system with multiple shipment policy, International Journal of Production Economics, 102(2), 302-316, 2006.

9. M. J. Rosenblatt and H. L. Lee, Economic production cycles with imperfect production processes, IIE Transactions 18, 48-55, 1986.

10. T. C. E. Cheng, An economic order quantity model with demand-dependent unit production cost and imperfect production processes, IIE Transactions, 23, 1991, 23-28.

11. K. Moinzadeh and P. Aggarwal, Analysis of a production/inventory system subject to random disruptions, Management Science 43, 1577-1588, 1997.

12. M. A. Rahim and M. Ben-Daya, Joint determination of production quantity, inspection schedule and quality control for imperfect process with deteriorating products, Journal of the Operational Research Society 52, 1370-1378, 2001.

13. Y-S. P. Chiu, S. W. Chiu, and H-D. Lin, Solving an EPQ model with rework and service level constraint, Mathematical \& Computational Applications, 11(1), 7584, 2006.

14. T. Dohi, N. Kaio, and S. Osaki, Minimal repair policies for an economic 
manufacturing process, Journal of Quality in Maintenance Engineering 4, 248262, 1998.

15. Y. P. Chiu, Determining the optimal lot size for the finite production model with random defective rate, the rework process, and backlogging, Engineering Optimization 35, 427-437, 2003.

16. A. M. M. Jamal, B. R. Sarker, and S. Mondal, Optimal manufacturing batch size with rework process at a single-stage production system, Computers \& Industrial Engineering 47, 77-89, 2004.

17. S. W. Chiu and Y-S. P. Chiu, Mathematical modeling for production system with backlogging and failure in repair, Journal of Scientific \& Industrial Research, 65 , 499-506, 2006.

18. Y-S. P. Chiu, C-Y. Tseng, W-C. Liu, and C-K. Ting, Economic manufacturing quantity model with imperfect rework and random breakdown under abort/resume policy, P I Mech E Part B: Journal of Engineering Manufacture 223, 2, 183-194, 2009.

19. G. C. Lin and D. E. Kroll, Economic lot sizing for an imperfect production system subject to random breakdowns, Engineering Optimization 38, 73-92, 2006.

20. Y-S. P. Chiu, K-K. Chen, F-T. Cheng, and M-F. Wu, Optimization of the finite production rate model with scrap, rework and stochastic machine breakdown, Computers and Mathematics with Applications, 59(2), 919-932, 2010.

21. Y-S. P. Chiu and C-K. Ting, A note on 'Determining the optimal run time for EPQ model with scrap, rework, and stochastic breakdowns', European Journal of Operational Research, 201(2), 641-643, 2010.

22. S. W. Chiu, D-C. Gong, C-L. Chiu, and C-L. Chung, Joint determination of the production lot size and number of shipments for EPQ model with rework, Mathematical and Computational Applications, 16(1), 2010 (article in press).

23. R. W. Grubbström and A. Erdem, The EOQ with backlogging derived without derivatives, International Journal of Production Economics, 59, 529-530, 1999.

24. L. E. Cárdenas-Barrón, The economic production quantity (EPQ) with shortage derived algebraically, International Journal of Production Economics, 70, 289292, 2001.

25. S. W. Chiu, C-B. Cheng, M-F. Wu, and J-C. Yang, An algebraic approach for determining optimal lot size for EPQ model with rework process, Mathematical and Computational Applications, 15(3), 364-370, 2010. 